Vol 11, Issue 8, 2018

\title{
CHRONOTHERAPEUTIC DRUG DELIVERY SYSTEM: AN EMERGING APPROACH TO TREAT CIRCADIAN RHYTHMIC RELATED DISEASE
}

\author{
ANUTTAM KUILA, NAGASAMY VENKATESH DHANDAPANI*, HIMANGSHU BHOWMIK, ABHISHEK SONI, \\ KAMMARI HARISH KUMAR
}

Department of Pharmaceutics, JSS College of Pharmacy, Ootacamund, JSS Academy of Higher Education \& Research, Mysuru - 643 001, India. Email: nagasamyvenkatesh@jssuni.edu.in

Received: 23 March 2018, Revised and Accepted: 24 April 2018

\begin{abstract}
The research on chronotherapy has garnered interest from scientists to understand circadian rhythms and their applications in the biological system. The area of chronotherapeutics covers essential information which is helpful to move forward and solve entanglements in current drug delivery technology. Chronotherapy is the conveying drugs in the body at the target site by maintaining perfect synchronicity with circadian rhythms. The main aim of the current rhythmic research is to formulate and design a therapeutic novel system which can deliver the drug in a desired way inside the body to treat various rhythmic diseases according to their occurrence. Drug release from an ideal chronotherapeutic system should be rapid, and the release of drug from the delivery system should also be complete after a specific or defined lag time period. Recently, scientists are involved in developing chronotherapeutic drug delivery system to treat chronological diseases such as single and multiple units using an erodible, soluble or insoluble polymer coating, and stimuli regulated drug delivery systems. In this review, we focus on the elaboration of the concept of chronotherapy, main challenges ahead during its development process, current approaches and its future applications in drug delivery in the treatment of circadian rhythmic diseases.
\end{abstract}

Keywords: Circadian rhythms, Chronotherapy, Pulsatile drug delivery, Lag time, Stimuli.

(c) 2018 The Authors. Published by Innovare Academic Sciences Pvt Ltd. This is an open access article under the CC BY license (http://creativecommons. org/licenses/by/4. 0/) DOI: http://dx.doi.org/10.22159/ajpcr.2018.v11i8.26169

\section{INTRODUCTION}

The biological cycle is a very common phenomenon for all living organism especially mammals. It is been found as a change of genetic response according to time in the external environment. There are mainly three different types of biological rhythms which are observed in humans such as:

- Ultradian rhythms $(<24 \mathrm{~h})$

- Circadian rhythms (24 h)

- Infradian rhythms

In 1959, Franz Helberg first used the word "circadian" which was derived from two Latin words "circa" means about and "dies" means day [1-6]. Studies show that circadian rhythms, which are independent and endogenous oscillation and happens within $24 \mathrm{~h}$ as a cyclical way and sleep-wake cycle that is based on the internal biological clock of humans or other mammals. Furthermore, the functions of lots of body organs vary with the specific daytime so the progression of some diseases has specific temporal and systemic patterns during its manifestation $[7,8]$. Various diseases such as angina pectoris, hypertension, blood pressure, and diabetes can be called as circadian rhythmic disorders $[9,10]$

Angina pectoris has the chances of occurring early in the morning for the patients who are suffering from this disease. Blood pressure goes down in the morning after wake up hours or during wake up hours [11].

Hence, the treatment of this disease need special novel dosage form because with immediate release or conventional dosage forms patient non-compliance will arise especially for the patients who are affected by angina pectoris, hypertension like diseases because in both the cases patients have to take their medicines in early in the morning (at 4 or $5 \mathrm{am}$ ). For most of the patients, it's very difficult to take these medications in the early morning on a daily basis [12]. There have been many dosage forms such as controlled and sustained release drug products which give controlled and effective blood-drug concentrations for a long period of time but the main error occur while treatment with this dosage forms is adverse effects in various patients [13].

In this kind of situation, scientists have done many types of research on the treatment of chronological disease. Their researchers mainly focused to develop a dosage form such a way that it can treat this kind of diseases with ease and show better patient compliance. Due to having various degrees of intensity as higher, middle, and lower at a particular timing of a day, studies have shown that these diseases can only be treated by giving the right medicine at the right dose at the right time to the right patients [14]. Capsule and tablet preparations are being used as a pulsatile drug delivery system (PDDS). Tablets are designed as a reservoir system which may be coated with erodible barriers. Most of the capsule preparations prepared using semi-permeable layers and a hydrogel polymer plug engineered along with it $[15,16]$.

For this reason, scientists or formulators have devoted themselves to design a dosage form in such a way that it must release the drug after a lag time according to the timing of the occurrence of the disease. This kind of dosage forms is known as PDDS. The concepts of the biological clock in reference to the timing of manifestation of diseases are shown in Fig 1.

\section{WHY WE NEED CHRONOTHERAPEUTIC DRUG DELIVERY?}

\section{Biological tolerance}

Drugs such as salbutamol sulfate and nitroglycerine have shown biological tolerance after its administration because these drugs have the tendency to remain on target site and maintained a continuous drug release plasma profile. Therefore, it will be the cause of the reduction in the therapeutic action of these drugs.

\section{Chronotherapeutic conditions}

Several body functions and the activity of many organs is chained with time and show circadian rhythm. As well as, it also affects other functions of the 
body such as acid secretion and hormonal secretion. Researchers also have shown that there are many diseases which are synchronized with time.

\section{First-pass metabolism}

Beta blockers and salicylamide are the examples of drugs which undergo a huge amount of first-pass metabolism. It is necessary to minimize the presystemic metabolism of these substances to get better oral-bioavailability.

\section{Local therapeutic need}

If we see it as a point of view of patient comfort and better therapeutic action, application of pulsatile drug delivery in local or inflammatory disorders can give better results over other dosage forms. It is designed to give the desired therapeutic action by releasing the drug at the various part of gastrointestinal tract.

\section{Gastric irritation}

There are various drug substances which are the main reason behind gastric irritation and chemical instability in stomach area in the body. In this case, controlled and sustained release dosage forms cannot be used because it may aggravate the chemical instability and irritation in git fluid [17-19].

\section{DOMINANCE OVER OTHER DOSAGE FORMS}

- Administration of two different simultaneously would be possible.

- It protects the drug to be deterred in the stomach.

- Risk of dose dumping can be avoided.

- Inter-intra subject is reduced.

- Drug releases from the system after a designed lag time according to according to the timing of the disease.

- Lower dosing frequency.

- Fewer side effects.

- It shows better specificity in pharmaceutical activity.

- Better patient's compliance $[20,21]$.

\section{DRAWBACKS OF PDDS}

- Less manufacturing effectiveness.

- The requirement of advanced technology.

- Skillful formulators are required for manufacturing and designing of this kind of formulation [22]

\section{CHRONOTHERAPEUTIC APPROACHES TO DESIGNING A DRUG DELIVERY}

\section{Single unit}

Improved osmotic devices and capsule-shaped systems are used as a single unit drug delivery system. Studies show that therapeutic agents

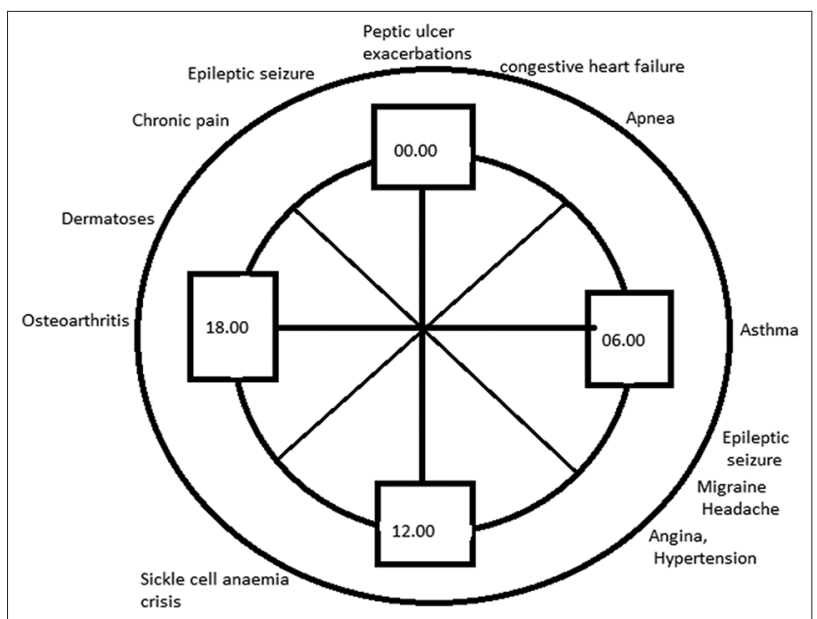

Fig. 1: Manifestation of diseases according to biological clock of the body which are meant to administer the body to attain time-controlled pulsatile release characteristic can be done successfully using capsuleshaped systems. In this system, the drug contents which are present inside capsule body generally integrated by swellable hydrogel cap. It has the ability to release the drug immediately after a specified lag time just after its contact with a dissolution fluid and this release process accomplished by the swelling mechanism of the plug layer. Due to hydrophilic nature of the plug layer, it is capable of removing itself from the capsule body which is insoluble in nature. Hydrophilic polymers are used to establish this type of plug layer. Polyethylene oxide, hydroxypropyl methylcellulose, and polyvinyl alcohol are the polymers which are generally used in this kind of novel capsular shaped systems $[23,24]$.

Single unit drug delivery systems are designed as:

- Systems based on osmosis

- Other capsule-shaped devices.

\section{Multiparticulate system}

The main reason behind designing of multiple unit systems because scientists have discussed a fact that it has all the characteristic of the single unit system and has shown various advantages over other dosage forms. This type of system was designed by some specific approaches which are given below:

- The rupturable polymer coating on a reservoir system

- The soluble or erodible polymer coating on a reservoir system

- Change in membrane permeability

- Low density is floating multiparticulate system [25].

There are so many factors which can possibly affect the drug release from these systems such factors are physicochemical properties of the drug, amount of excipients and drugs used in the formulation as well as environmental factors also can influence the drug release mechanism. The different examples of the single unit system and the multiparticulate system have been shown in Table 1 .

\section{Stimuli induced}

These systems basically used as a site-specific drug delivery system which is been developed according to the physiochemical process of the body. Various stimuli such as temperature and chemical stimuli such as ph, enzyme release, hormone secretion, glucose, and insulin influence the release of drug from this system $[31,32]$.

\section{Temperature}

In the case of many stimuli induced system, temperature considered as one of the most used triggering signals. Various formulators or research scientists have developed many drug delivery systems which are temperature responsive. It is being designed in kind of way that it will influence the properties of polymers used in the system by the assistance of temperature as a triggering signal. It has the ability to change polymers properties just as crystalline melting, swelling or de-swelling mechanism of polymers, and thermally reversible coil/globule transition [31].

\section{Chemical stimuli influenced systems}

Glucose-responsive insulin release devices, inflammation induced release systems; pH-sensitive systems are the examples of chemical stimuli induced system. These systems have designed a way that release of drugs from the system caused by biological stimuli.

Disorders like diabetes mellitus show rhythmic changes of glucose level in the body at a particular time of a day. This case demands a proper efficacious dosage form which will deliver insulin at a perfect time. Systems like ph hydrogels are being used to treat this kind of disease. It consists of glucose oxidase as the main constituent which will bring changes in the $\mathrm{pH}$ by transforming the glucose into gluconic acid at the time of increased glucose level in the blood. This mechanism of swelling of polymer helps the system to release the drug in a perfect way [32]. Recently scientists formulate a unique gel formulation which acts as a stimuli-sensitive system by forming a complex with stimuli [32]. 
Table 1: Example of various pulsatile drug delivery in the market [25-30]

\begin{tabular}{|c|c|c|}
\hline Approaches & Types of mechanism & Research \\
\hline \multirow[t]{2}{*}{ Single unit } & Osmosis & $\begin{array}{l}\text { The study explained in US487159, carried out using a } \\
\text { dissolution media in which this kind of system has been } \\
\text { located to see the process of eruption of plug layer }\end{array}$ \\
\hline & Capsule-shaped devices & $\begin{array}{l}\text { Scientists had designed a pulsatile drug delivery system } \\
\text { in which they developed an inner core that contains the } \\
\text { drug, various osmotic agents, and hydrophilic polymers. } \\
\text { A semi-permeable membrane had been used as a layer } \\
\text { coating. Due to water influx process, the core of the system } \\
\text { starts to swell }\end{array}$ \\
\hline \multirow[t]{4}{*}{ Multiparticulate system } & The rupturable polymer coating on a reservoir system & $\begin{array}{l}\text { Scientist developed a system in which they used sodium } \\
\text { chloride, MCC which was further coated with ethyl-cellulose } \\
\text { along with methacrylic acid and link forming agents were } \\
\text { also been used }\end{array}$ \\
\hline & The soluble or erodible polymer coating & $\begin{array}{l}\text { In } 1995 \text {, scientist had designed pulsatile drug delivery } \\
\text { system in which they divided the tablet structure into the } \\
\text { inner core, the outer core of the tablet was coated with } \\
\text { various viscosity grade HPMC }\end{array}$ \\
\hline & Change in membrane & $\begin{array}{l}\text { A system shows pulse release process after alteration of } \\
\text { diffusion characteristics of Eudragit RS polymers }\end{array}$ \\
\hline & Low-density floating multiparticulate system & $\begin{array}{l}\text { A porous hollow shaped calcium pectinate beads which were } \\
\text { developed by various researchers }\end{array}$ \\
\hline
\end{tabular}

MCC: Micro crystalline cellulose, HPMC: Hydroxylpropyl methylcellulose

\section{Externally regulated drug delivery systems}

When some external stimuli such as radiation, ultrasound, electrical effect, and the magnetic field applied on a system and which will be sensitized to stimulate the release of drug as well as when the external stimuli discharged from the system at that time the release process from the device will be discontinued. Recently, advancements in regulated system bring various external regulated systems. It has been developed to target the drug effectively at the site of action and reduces the chances of side effects by giving the drug at a right amount [33]. The photochemically controlled drug delivery system is an externally regulated drug delivery which is produced by polymerization of polyamide microcapsules interfacially. Implanted magnetic beads usually called this kind of drug delivery system [34].

\section{EVALUATION OF PDDS}

\section{Bulk density}

The bulk density of the powder is defined as a ratio of powder mass to the bulk volume. It relies on the cohesiveness of granules, shape, and distribution of particle size of granules. Powder should be accurately weighed than poured carefully inside a graduated measuring cylinder by a funnel. After that, the volume must be measured which is calculated as the initial volume of the bulk. It is calculated by applying an equation which is described as follows:

$\mathrm{Db}=\mathrm{M} / \mathrm{Vo}$

Vo=The bulk volume of the powder

$\mathrm{M}=$ Powder mass.

\section{Tapped density}

Unit of tapped density is $\mathrm{g} / \mathrm{mL}$ and described as an equation:

$\mathrm{Dt}=\mathrm{M} / \mathrm{Vt}$

$\mathrm{M}$ is the mass of powder,

$\mathrm{Vt}$ is the tapped volume of the powder.

\section{Diameter and thickness of the tablet}

It is measured by Vernier Calipers. To bring consistency in size and shape of tablets measurement of thickness and diameter is considered as an important process for formulators.

\section{Hardness}

The Monsanto hardness tester which consists an adjusted scale is the equipment which is been used to determine the hardness of tablets.
This experiment is carried out to distinguish a fact that how much strength of a tablet to be required during storage, transportation, and handling process through calculating it in terms of $\mathrm{kg} / \mathrm{cm}^{2}$.

\section{Content uniformity and weight uniformity of the dosage forms}

As per Indian Pharmacopoeia, there is a guideline given in which it is been described that uniformity of weight and uniformity of API present in each tablet must be within a specified range. Thus, these tests are operated to verify to establish a dosage form which will be perfectly set within the acceptable range as per the guidelines.

\section{In vitro buoyancy determination}

The floating characteristics of the tablet in gastro floating drug delivery system have a significant effect on the in vivo behaviour of the drug. Hence, it is essential to determine the floating mechanism of the dosage form.

\section{In vitro dissolution test}

The types of a dosage form which are going to be tested according to that various USP dissolution apparatus will be used. The whole experiment will be carried out under specified $\mathrm{pH}$ and medium. UV double beam spectrophotometer is used after collecting the samples at a regular time intervals for analysis.

\section{Floating lag time}

It is useful to determine the time when a tablet appears in the liquid after addition of the dissolution medium.

\section{Total floating time}

It is carried out to check the timing of the floating process of tablet layer. Comparison of floating lag time and total floating time is given in Table 2.

\section{Swelling index (SI)}

Accurately weighed tablets should be kept in distilled water $(50 \mathrm{ml})$. Then, $1 \mathrm{~h}$ letter tablets should be removed from the container, after that water present on the surface should be removed using filter paper now the accurate measurement of weighed should be done. Percentage SI was investigated using the formula:

SI=(Wet weight-Dry weight/Dry weight $) \times 100$

\section{Rupture test}

It is carried out on coated tablets. The equipment used in this is USP paddle apparatus. Its experiment process was same as in vitro 
Table 2: Comparison of floating lag time and total floating time

\begin{tabular}{lll}
\hline Parameters & Floating lag time & Total floating time \\
\hline $\mathrm{pH}$ & 1.2 & 1.2 \\
Rotation & 50 & 50 \\
Temperature & $37 \pm 0.5^{\circ} \mathrm{C}$ & $37 \pm 0.5^{\circ} \mathrm{C}$ \\
Medium & Dissolution medium & Gastric fluid \\
\hline
\end{tabular}

dissolution method. The lag-time generated during rupturing process of coated tablets (film or enteric coating) calculated using rupture test [35-38]

\section{DIFFICULTIES}

- Rhythmic biomaterials and designing of the system

- Engineering and modeling the release patterns of the drug from the system

- Regulatory guidelines.

These obstacles are considered as major challenges to developing a suitable PDDS [39].

\section{Rhythmic biomaterials and designing of the system}

Drug products that are intended for chronotherapeutic research have been developing recently although the true breakthrough in chronotherapy will only be promising with smarter biomaterials [40].

In past decades, major steps have been taken in developing and designing of smart and safe rhythmic biomaterials. There are still areas to progress in developing smarter rhythmic biomaterials that are not only biocompatible but also a stimulus to some specific biomarkers. By implying a fast and rhythmic treatment for specific rhythms or biomarkers are the solution to this condition [39].

Currently, the application and development of chemical oscillators and stimuli-sensitive polymers are the top priority in the development and designing of the rhythmic biomaterials [41].

\section{Rhythmic engineering and modeling}

One of the major obstacles in chronotherapeutic drug formulation is barriers in producing a promising model which will be helpful to figure out the relationship of physiological properties of these dosage forms with their biological responses [42].

\section{Regulatory hurdles}

In the pursuit of a promising delivery system which would be extensively accepted in the medical practice as well as in the public market, the top priority is to understand the current regulatory concerns and the technical difficulties. Although the researchers and scientists are working according to the regulatory concerns and requirement, that is not the case in academics which are progress by the proofs of theories and concepts without any regulatory concerns [43]. Pre-approval and post-approval phases are the major considerations in developing a pulse delivery system.

\section{Pre-approval phase}

It is sometimes complicated to display the chronotherapeutic application of modified and controlled release formulation in clinical therapy. This is fairly associated with the first two hurdles especially the lack of rhythmic tools and the lack of rhythmic yodeling and précised rhythmic biomaterials. Since the modified release delivery systems pose distinctive challenges in the development of the drug delivery system, specific studies are required to characterize the release patterns or nature of the formulation. Due to the stringent regulatory guidelines and specificity of these studies, the pharmaceutical researches works parallel with the requirements of regulatory agencies and cross referencing the relevant parameters which are accordingly controlled.
Under the US Code of Federal Regulations 21CFR 320.25, the requirements of bioavailability studies for controlled release formulations are covered [44]. Under the US Code of Federal Regulations 21CFR 314.54, approved immediate release products of some active ingredients are covered [45].

\section{Post-approval phase}

The major challenges before the regulators and formulators to realize abuse of the drug and to prevent counteract the abuse. Briefly, the factors that might bestow the drug material for abuse should be considered by the regulators and formulators and should come up with proper precautions and risk management strategies which can be applied post-approval. The alternative for rejecting a product where there is an insight that the drug substance may pose an extensive threat to the population is approval with the safety studies and restricted use or distribution are given in the US Code of Federal Regulations 21 CFR 314.520 [46]. The FDA has been having heavily dependent on risk management strategies and various programs to approve the drug while implementing any restrictions.

\section{FUTURE PERSPECTIVE}

There are countless scientific proofs deriving out from various stages of clinical or chronological studies firmly indicating the fact that clinical applicability of chronotherapeutic drug delivery stands on the basis of its theoretical along with experimental backgrounds and also the approval of marketing process depends on this concept [47]. Although, this system is turning out to be an emerging and novel concept for efficient drug delivery. Because it has a huge potential toward the treatment of various diseases which are considered as circadian rhythmic disorders and it shows better patient acceptance or patient comfort over another dosage form. However, there are various obstacles coming out as building blocks such as finding out proper rhythmic biomaterials and designing and engineering related problems regarding development [48]. Hence, the proper development and designing of these systems can be possible only after minimizing these risk factors. Recently, scientists are working spontaneously to establish better, productive and newer technologies a way by which they can deal with this situation effortlessly. To secure the future of this system, already scientists have taken their step forward as their studies become more aware of bringing out destined advancements in timing synchronization, nanotechnology or nanomedicines, and system biology [49]. In future, there are lots of areas such as cost-effective manufacturing process, dose flexibility, and choosing of relevant technologies related problems need to be taken seriously and the future steps toward these challenges have given in Table 3 and the marketed formulations are shown in Table 4.

\section{CONCLUSION}

Since considering this fact, circadian rhythms have a special connection with the occurrence of many diseases. Therefore, a special novel drug delivery system is required for the treatment of these chronological diseases. For this reason, experts predict a continuously rising market for PDDS. Recently, so many efforts have been taken which will fulfill the requirements of patients regarding compliance, therapeutic actions. However, sustained or controlled drug delivery is not enough for the treatment of these diseases. Thus, pulsatile drug delivery is the ideal system which is releasing the drug at the right time, with right dose and at the target site. These characteristics are found to be lacking in sustained or controlled release and immediate release formulations.

It also strictly correlates the circadian rhythms of the body by maintaining the optimal concentration of drug at diseased state. There have various obstacles to developing a pulsatile drug delivery over other dosage forms, but still, it is arising as an exceptional tool to target the drug at the site of action and the treatment of various chronological disorders. 
Table 3: Various challenges and future perspective toward this challenge

\begin{tabular}{|c|c|}
\hline Example of various challenges & Future prospective towards these challenges \\
\hline Lack of reliable biomaterials & Launching and designing of new smarter biomaterials \\
\hline Issues related to various rhythmic biomaterials to certain stimulus. & $\begin{array}{l}\text { Introduction of stimuli-sensitive polymers (ph oscillators to } \\
\text { drive rhythmic drug delivery). }\end{array}$ \\
\hline $\begin{array}{l}\text { Many biomaterials reactive to external stimuli such as electric field, chemicals } \\
\text { temperature, pH, and light. It leads to changes in the molecular behavior } \\
\text { of these biomaterials. This will possibly change the surface characteristics, } \\
\text { shape, solubility, moisture intake, and stability }\end{array}$ & $\begin{array}{l}\text { Light-induced-chronopharmaceutical delivery system } \\
\text { Microchips based drug delivery system }\end{array}$ \\
\hline \multirow[t]{3}{*}{$\begin{array}{l}\text { Issues related to the establishment of safe, efficacious models, and } \\
\text { engineering the body rhythm }\end{array}$} & $\begin{array}{l}\text { Rossler models: The newly approved model consists of three } \\
\text { differential equations. It shows perfect dynamics }\end{array}$ \\
\hline & $\begin{array}{l}\text { An array of electrochemical reactions and various phase } \\
\text { models have the utility to tune any complicated dynamics } \\
\text { structures to a desired simple model that shows the desired } \\
\text { response }\end{array}$ \\
\hline & $\begin{array}{l}\text { Other models such as a numerical algorithm have been used to } \\
\text { calculate the swelling mechanism of polyelectrolyte gel }\end{array}$ \\
\hline
\end{tabular}

Table 4: Marketed products

\begin{tabular}{|c|c|c|c|c|c|}
\hline Mechanism & Technology & Product name & Drugs & Disorders & Manufacturer \\
\hline Osmosis & Covera-HS ${ }^{\circledR}$ & OROS $^{\circledR}$ & $\begin{array}{l}\text { Verapamil } \\
\text { HCL }\end{array}$ & Hypertension & Alza Corporation \\
\hline $\mathrm{pH}$ & Verelan ${ }^{\circledR} \mathrm{PM}$ & CODOS $^{\circledR}$ & $\begin{array}{l}\text { Verapamil } \\
\text { HCL }\end{array}$ & Hypertension & Elan Drug Technologies \\
\hline External stimuli & Their Form ${ }^{\circledR}$ & 3D printing ${ }^{\circledR}$ & Diclofenac sodium & Inflammation & - \\
\hline Rupturable layer & PulsincapTM & PULSINCAP ${ }^{\circledR}$ & Dofetilide & Hypertension & R. P. Scherer International Corporation \\
\hline $\begin{array}{l}\text { Soluble/insoluble polymer } \\
\text { coating }\end{array}$ & MoxtagTM & PULSYS ${ }^{\circledR}$ & Amoxicillin & Antibiotics & Middlebrooks Pharmaceuticals, USA \\
\hline
\end{tabular}

\section{AUTHOR'S CONTRIBUTION}

All the authors were equally contributed to the collection of data, gathering information, writing, critical review, and design of a framework of the manuscript.

\section{CONFLICTS OF INTEREST}

The authors of this manuscript confirm that this article content has no conflicts of interest.

\section{REFERENCES}

1. Sewlall S, Pillay V, Danckwerts P, Choonara EY, Ndesendo MK, $\mathrm{Du}$ Toit LC. A timely review of state-of-the-art chronopharmaceuticals synchronized with biological rhythms. Curr Drug Deliv 2010;7:370-88.

2. Schibler U. The daily rhythms of genes, cells, and organs. EMBO Rep 2005;6:9-13.

3. Oishi K, Ohkura N, Kadota K, Kasamatsu M, Shibusawa K, Matsuda $\mathrm{J}$, et al. Clock mutation affects circadian regulation of circulating blood cells. J Circadian Rhythms 2006;4:1-7.

4. Froy O. The relationship between nutrition and circadian rhythms in mammals. Front Neuroendocrinol 2007;28:61-71.

5. Beckett M, Rode LC. Mechanisms by which circadian rhythm disruption may lead to cancer. S Afr J Sci 2009;105:11-2.

6. Rana S, Mahmood S. Circadian rhythm and its role in malignancy. J Circadian Rhythms 2010;8:1-13.

7. Mazuski C, Herzog ED. Circadian rhythms: To sync or not to sync. Curr Biol 2015;25:337-9.

8. Romano S, Chacko SJ, Rangarajan V, Chung J, Farzaneh AF. Resistant hypertension. Am J Med 2015;128:23-5.

9. Chen K, Wang Y, Gai X, Wang H, Li Y, Wen H, et al. Design of a time-controlled pulsatile release system for propranolol using the drycoated method: In vitro and in vivo evaluation. AAPS Pharm Sci Tech
2017;18:2683-90.

10. Hong YJ, Jeong MH, Cho KH, Kim MC, Lee KJ, Kim KH, et al. Impact of renal function on changes of plaque characteristics in non-intervened coronary segments after rosuvastatin treatment in patients with angina pectoris and hypertension. Int J Cardiol 2015;187:286-7.

11. Thitinan S, Mc Conville JT. Development of a gastroretentive pulsatile drug delivery platform. J Pharm Pharmacol 2012;64:505-16.

12. Arafat MO. Approaches to achieve an oral controlled release drug delivery system using polymers: A recent review. Int J Pharm Pharm Sci 2015;7:16-21.

13. Shishehbori F, Mortazavia SA, Jafariazar Z, Rad RT. Formulation and in vitro evaluation of ketoprofen gastric floating matrix tablet based on gas formation. Int J Appl Biol Pharm 2015;6:85-93

14. Gandhi S, Gosse MD, Nishii Y, Nuxoll E. Barrier-mediated pulsatile release. J Membr Sci 2015;495:351-60.

15. Shidhaye S, Lotlikar V, Ghule A, Phutane P, Kadam V. Pulsatile delivery systems: An approach for chronotherapeutic diseases. Sys Rev Pharm 2010;1:55

16. Vemula SK. Formulation and pharmacokinetics of colon-specific double-compression coated mini-tablets: Chronopharmaceutical delivery of ketorolac tromethamine. Int J Pharm 2015;491:35-41.

17. Parmar RD, Parikh RK, Vidyasagar G, Patel DV, Patel CJ, Patel BD. Pulsatile drug delivery systems: An overview. Int J Pharm Sci Nanotech 2009;2:6-5.

18. Jain SS, Agarwal HV, Jagtap PS, Dand NM, Jadhav KR, Kadam VJ. Pulsatile drug delivery system (PDDS): A Brief overview. Res J Pharm Technol 2012;5:449-61.

19. Saigal N, Baboota S, Ahuja A, Ali J. Site-specific chronotherapeutic drug delivery systems: A patent review. Recent Pat Drug Deliv 2009;3:64-70

20. Patel MM. Colon: A gateway for chronotherapeutic drug delivery systems. Expert Opin Drug Deliv 2015;12:1389-95.

21. Rompicharla B, Prabha KS, Tabasum MD. A comprehensive review of pulsatile drug delivery system. Int Res J Pharm 2012;3:106-8. 
22. Gupta A. Review on recent advances in pulsatile drug delivery system: A vision for better future for treatment of diseases. Int Pharm Sci 2012;2:71-6.

23. Gandhi BR, Mundada AS, Gandhi PP. Chronopharmaceutics: As a clinically relevant drug delivery system. Drug Deliv 2011;18:1-8

24. Sangalli ME, Maroni A, Zema L, Busetti C, Giordano F, Gazzaniga A. In vitro and in vivo evaluation of an oral system for time and/or sitespecific drug delivery. J Control Release 2001;73:103-110.

25. Singh V, Deshpande A. The emergence of time programmed drug delivery system: Chronotherapy of cardiovascular diseases. Int J Pharm Pharm Sci 2014;6:56-60.

26. Ueda Y, Hata T, Yamaguchi H, Ueda S, Kodani M, inventors; Fujisawa Pharmaceutical Co Ltd, assignee. Time-Controlled Explosion Systems and Processes for Preparing the Same. United States patent US 4,871,549; 1989

27. Kok PH, Vonk P, Kossen NW. A particulate pulse-release system and mathematical description with the Maxwell-Stefan theory. J Control Release 2000;66:293-306

28. Gazzaniga A, Busetti C, Moro L, Crimella T, Sangalli M, Giordano F. Evaluation of low viscosity HPMC as retarding coating material in the preparation of time-based oral colon-specific delivery system. Proc Int Symp Control Release Bioact Mater 1995;22:242-3.

29. Narisawa S, Nagata M, Danyoshi C, Yoshino H, Murata K, Hirakawa Y, et al. An organic acid induced sigmoidal release system for oral controlled release preparation. Pharm Res 1993;11:111-6.

30. Badve SS, Sher P, Korde A, Pawar AP. Development of hollow/porous calcium pectinate beads for floating-pulsatile drug delivery. Eur J Pharm Biopharm 2007;65:85-93.

31. Pawar VK, Awasthi R. Chronotherapy: An approach to synchronize drug delivery with circadian rhythm. J Chronother Drug Deliv 2010;1:1-8.

32. Singh DK, Poddar AS, Nigade SU, Poddar SS. Pulsatile drug delivery system: An overview. Int J Curr Pharm Res 2011;2:55-80.

33. Nagar M, Singhai S, Chopra VS, Gautam N, Trivedi P. Chronotropic systems; an emerging trend in drug delivery for pulsed release in chronopharmacotherapy. Int J Pharm Clin Res 2010;2:10-9.

34. Ashwini D, Asif K, Ramana MV, Mitul P, Omkar D. Chronotherapy: A novel drug delivery system. Int $\mathrm{J}$ Res Ayurveda Pharm 2011;2:1692-700.
35. Shanmugan P, Bandameedi R. Chronotherapeutic drug delivery systems. J Drug Metab Toxicol 2015;6:2

36. Jain D, Raturi R, Jain V, Jain V, Bansal P, Singh R. Recent technologies in pulsatile drug delivery systems. Biomatter 2011;1:57-65.

37. Maroni A, Sangalli ME, Cerea M, Busetti C, Giordano F, Gazzaniga A. Low viscosity HPMC coating of soft and hard gelatin capsules for delayed and colonic release: Preliminary investigations on process parameters and in vitro release performances. Proceed. Int Control Rel Bioact Mater 1999;26:87-8.

38. Nawle RB, Tadvee AA. Formulation and evaluation of time-release compression coated tablet containing acebrophylline for chronotherapy of asthma. Int J Pharm Pharm Sci 2014;6:231-7.

39. Youan BB. Chronopharmaceutical drug delivery systems: Hurdles, hype or hope? Adv Drug Deliv Rev 2010;62:898-903.

40. Langer R, Tirrell DA. Designing materials for biology and medicine. Nat 2004;428:487-92.

41. Koschwanez HE, Reichert WM. In vitro, in vivo and post explantation testing of glucose-detecting biosensors: Current methods and recommendations. Biomaterials 2007;28:3687-703.

42. Goldbeter A. Computational approaches to cellular rhythms. Nat 2002;420:238-45.

43. Youan BB. Chronopharmaceutics: Science and Technology for Biological Rhythm Guided Therapy and Prevention of Diseases. New Jersey: John Wiley and Sons; 2009. p. 384.

44. Midha KK, McKay G. Bioequivalence; Its history, practice, and future. AAPS J 2009;11:664-70.

45. Philip KA, Philip B. Chronopharmaceuticals: Hype or future of pharmaceutics. Curr Pharm Des 2011;17:1512-6.

46. Klasmeier C, Redish MH. Off-label prescription advertising, the FDA and the first amendment: A study in the values of commercial speech protection. Am J Law Med 2011;37:315-57.

47. Youan BB. Chronopharmaceutics: Gimmick or clinically relevant approach to drug delivery? J Control Release 2004;98:337-53.

48. Mandal AS, Biswas N, Karim KM, Guha A, Chatterjee S, Behera M, et al. Drug delivery system based on chronobiology-A review. J Control Release 2010;147:314-25.

49. Youan BB. Impact of nanoscience and nanotechnology on controlled drug delivery. Nanomed 2008;3:401-6. 